\title{
Behaviour of Surface Chloride Concentration in Concretes Subjected to Field Exposure in Marine Atmosphere Zone
}

\author{
Gibson R. Meira ${ }^{1}$, Pablo R. R. Ferreira ${ }^{2}$, Maria S. Freitas ${ }^{3}$ and Carmen Andrade ${ }^{4}$ \\ ${ }^{1}$ Paraíba Federal Institute, Civil and Environmental Eng. Post-graduate Program of UFPB, Av. João \\ da Mata, 256, 58015-020, João Pessoa, Brazil, gibsonmeira@yahoo.com, gibson.meira@ifpb.edu.br \\ ${ }^{2}$ Paraíba Federal Institute, Civil and Environmental Eng. Post-graduate Program of UFPB, Av. João \\ da Mata, 256, 58015-020, João Pessoa, Brazil, pablo.r06@hotmail.com, pablo.ferreira@ifpb.edu.br \\ ${ }^{3}$ Civil and Environmental Engineering Post-graduate Program of UFPB, Av. João da Mata, 256, \\ 58015-020, João Pessoa, Brazil, mariasilvajn@gmail.com \\ ${ }^{4}$ International Centre for Numerical Methods in Engineering (CIMNE), Campus Nord UPC C/ Gran \\ Capità, S/N 08034, Barcelona, Spain, candrade@ cimne.upc.edu
}

\begin{abstract}
Surface chloride concentration (Cs) is one of the parameters that feed models used to simulate chloride ingress into concrete. Therefore, understanding its behaviour over time is important for a more accurate forecasting. This work is part of a larger researcher project that aims to analyse the transport of chlorides into concrete in marine atmosphere zone based on long-term field exposures. The present paper focuses on the behaviour of Cs along 12.5 years. Prismatic concrete specimens with three different mixtures were exposed at places located at four different distances from the sea. Climatic variables and chloride deposition on the wet candle were parameters used to characterise the environment. Periodically, samples from concrete surface were extracted from the specimens and chemically analysed. Results show that Cs increases along the years and suggests a tendency of stabilisation over time, although this level could not be reached in the present exposure period. The relationship between $C s$ and chloride deposition rate on the wet candle was analysed and it was observed that the function $C s=C_{0}+k_{c s} .(D a c)^{n}$ is the one that best fits to experimental data.
\end{abstract}

Keywords: Concrete, Corrosion, Marine Atmosphere Zone, Surface Chloride Concentration.

\section{Introduction}

Surface chloride concentration $(C s)$ is one of the main parameters to feed models used to simulate chloride penetration into concrete structures. It has been observed that $C s$ tends to increase over the years (Costa and Appleton, 1999; Yang et al., 2017). However, this increase tendency weakens along time reaching a stabilisation, which can be observed after about ten years of exposure time in some cases (Andrade et al., 2000). This behaviour can be represented by some mathematical models, which are presented in Table 1, that shows functions proposed in literature to represent the behaviour of $C s$ in concrete structures exposed in marine atmosphere zone.

It can be observed that there are not many studies aimed on the behaviour of $C s$ and that most of functions are power or exponential functions, with a predominance of first one.

Analysing the results presented by the studies referenced in Table 1 it can be observed that, in general, $C s$ sharply increases in the first years and, in the following years of exposure, this trend gives way to a more understated increase. Depending on the function adopted to represent 
data behaviour, its final part can assume a more asymptotic shape, which denotes a stabilisation trend along the years. Moreover, in some cases Cs presents some fluctuation, which can be a result of the environmental interaction (Andrade et al., 2000; Meira, 2004).

Table 1. Literature models to represent surface chloride concentration behaviour in marine atmosphere zone.

\begin{tabular}{|c|c|c|c|c|}
\hline Source of data & Exposure time (years) & Function & Authors & Year \\
\hline Japan & $23-58$ & $C s=a . t^{0.5}$ & Uji et al. & 1990 \\
\hline Portugal & $0.5-5.5$ & $C s=a \cdot t^{b}$ & Costa and Appleton & 1999 \\
\hline United States of America & $2-16$ & $C s=a \cdot\left(1-e^{b . t}\right)$ & Kassir et al. & 2002 \\
\hline South Corea & $0.7-48.7$ & $C s=a \cdot \operatorname{Ln} \cdot(b \cdot t+1)+c$ & Pack et al. & 2010 \\
\hline Data from literature & $0-3$ & $C s=a+b . t^{0.5}$ & Zhou et al. & 2016 \\
\hline Data from literature & $0-5$ & $C s=a \cdot\left(1-e^{b . t}\right)$ & Yang et al. & 2017 \\
\hline
\end{tabular}

Regarding the shape of $C s$ curve, the continuous cement paste hydration along time is one of the aspects that may influence its behaviour. As hydration of cement paste advances, the concrete surface becomes less porous and less chloride ions can be captured in this region (Maheswaram and Sanjayan, 2004; Pack et al., 2010). As a consequence, the rate of Cs increase weakens. Besides that, the concrete ability in capturing chlorides decreases with the chloride

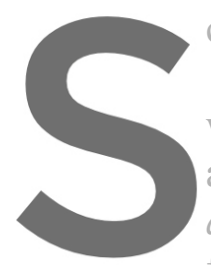
concentration increas $\phi$, which also contributes in the same wa

Another aspect to be which concrete structur a stronger increase of al., 1998; Costa and fluctuation, which can be related to the ions movement towards bulk concrete or to effects like surface chloride removal due to rainfall.

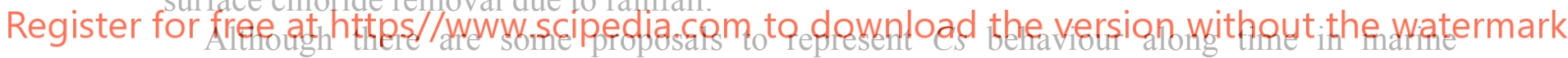
atmosphere zone, they are still scarce and there is no consensus related to the best function to represent $C s$ behaviour. This work contributes to this discussion and anaiyses the behaviour of $C s$ in concretes exposed along 12.5 years at a marine atmosphere zone located in northeast of Brazil. This is part of a project that studies the long-term chloride transport into concrete under natural exposure in marine atmosphere zone.

\section{Experimental Work}

Experimental work was based on environmental characterisation and chloride concentration measurements in concrete surface.

\subsection{Environmental Characterization}

The environmental characterization was done on temperature, relative humidity, rainfall, wind characteristics and sea-salt data. Climatic data were collected by a Brazilian Government weather station located in the region where the research took place. Sea-salt data was collected 
at places 10, 100, 200 and $500 \mathrm{~m}$ far from the sea (Figure 1 and Table 2) using the wet candle method, according to ASTM standard G140 (ASTM, 2014).
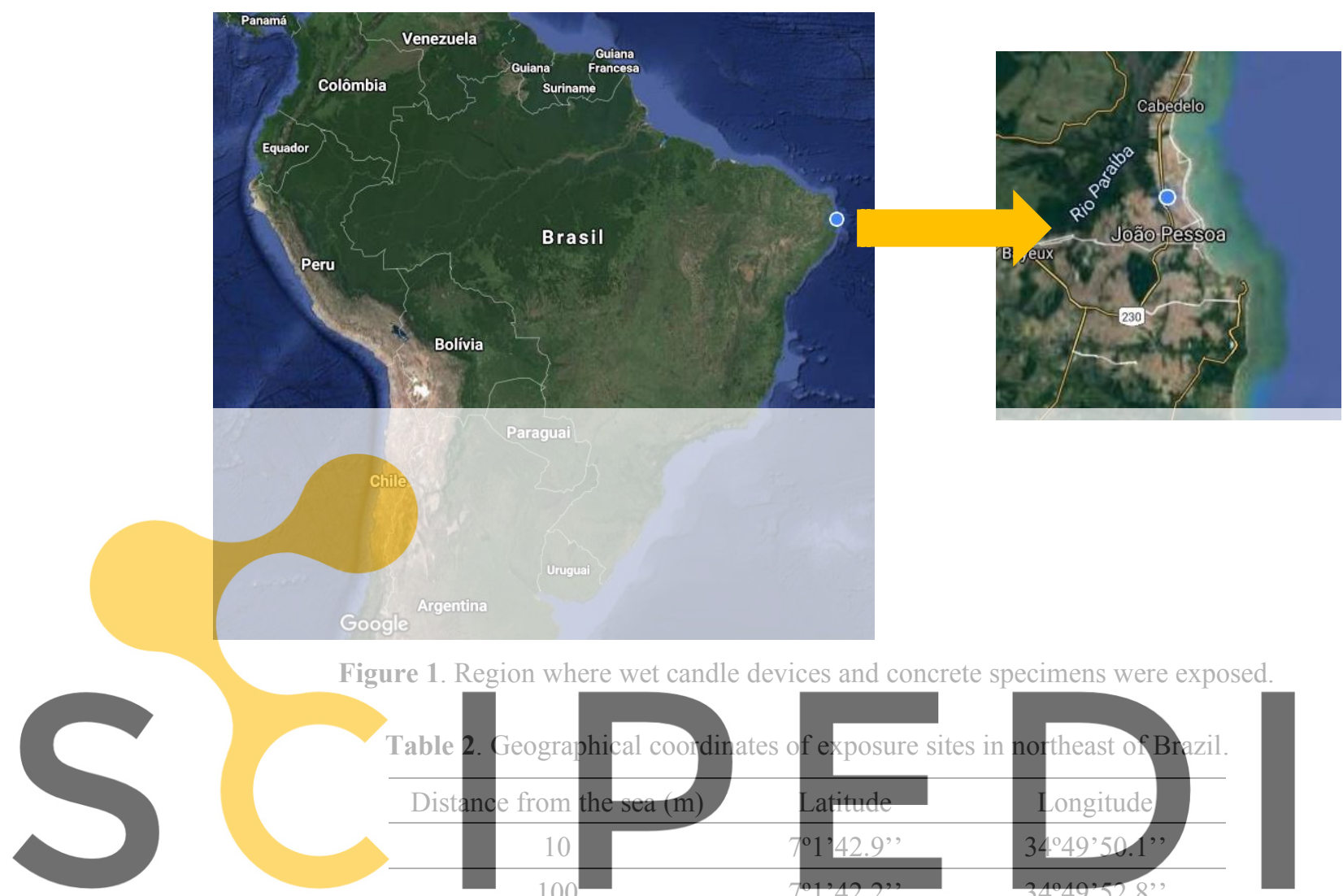

Figure 1. Region where wet candle devices and concrete specimens were exposed.
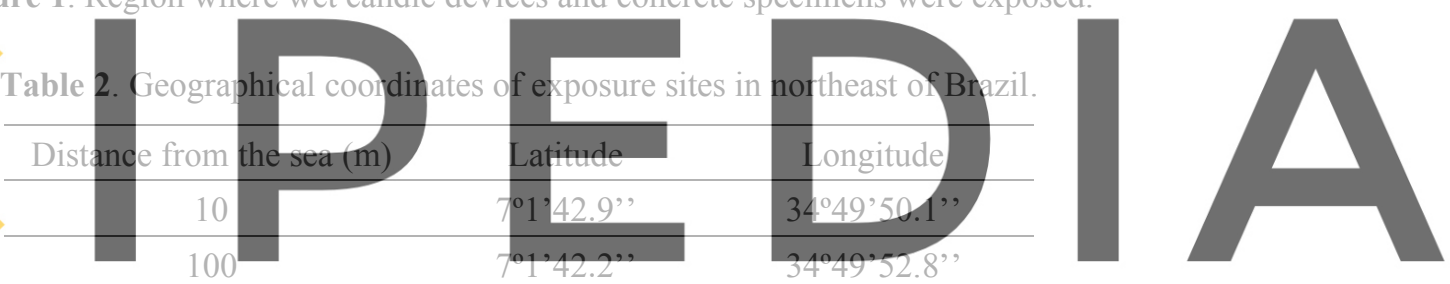

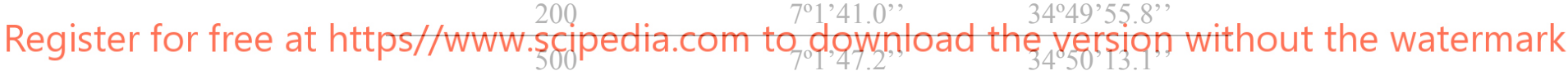

\subsection{Surface Chloride Concentration in Concrete}

Prismatic concrete specimens $(0.15 \times 0.15 \times 1.40 \mathrm{~m})$ were cast using a filler-modified Portland Brazilian cement, which chemical and physical properties are presented in Table 3. Concrete mixtures, with $\mathrm{w} / \mathrm{b}$ ratios between 0.65 to 0.50 , and physical properties are presented in Table 4. They are identified as C65, C57 and C50. Considering that these mixtures were performed a long time ago, they considered w/b that are not usual nowadays.

Table 3. Chemical and physical properties of used cement.

\begin{tabular}{lcccccccccc}
\hline $\begin{array}{l}\text { Composition } \\
(\%)\end{array}$ & $\mathrm{SO}_{3}$ & $\mathrm{SiO}_{2}$ & $\mathrm{Al}_{2} \mathrm{O}_{3}$ & $\mathrm{Fe}_{2} \mathrm{O}_{3}$ & $\mathrm{CaO}$ & $\mathrm{MgO}$ & $\mathrm{Na}_{2} \mathrm{O}$ & $\mathrm{K}_{2} \mathrm{O}$ & $\begin{array}{c}\text { Insoluble } \\
\text { residue (IR) }\end{array}$ & $\begin{array}{c}\text { Loss on } \\
\text { ignition (LI) }\end{array}$ \\
\cline { 2 - 9 } & 3.21 & 18.11 & 4.31 & 2.27 & 59.87 & 3.61 & 0.21 & 1.51 & 1.45 & 5.50 \\
\hline \multirow{8}{*}{ Property } & \multicolumn{8}{c}{3.06} \\
\cline { 2 - 9 }
\end{tabular}


Table 4. Concrete mixtures and properties.

\begin{tabular}{lccc}
\hline Concrete & C50 & C57 & C65 \\
\hline Mixture & & & \\
Cement $\left(\mathrm{kg} / \mathrm{m}^{3}\right)$ & 406 & 356 & 320 \\
Sand $\left(\mathrm{kg} / \mathrm{m}^{3}\right)$ & 769 & 812 & 840 \\
Coarse aggregate $\left(\mathrm{kg} / \mathrm{m}^{3}\right)$ & 947 & 947 & 947 \\
Plasticiser $\left(\mathrm{kg} / \mathrm{m}^{3}\right)$ & 1.22 & 1.06 & - \\
$\mathrm{w} / \mathrm{b}$ & 0.5 & 0.57 & 0.65 \\
\hline Property & & & \\
Slump $(\mathrm{mm})$ & 80 & 80 & 80 \\
Compressive strength $(\mathrm{MPa}-28$ days) & 31 & 27 & 20 \\
\hline
\end{tabular}

The specimens were cured in a wet chamber for 7 days and afterwards they were painted with a waterproof film at those surfaces thorough which chloride penetration should be avoided. Then, the specimens were placed at the same monitoring stations used for wet candle devices. After 6, 10, 14, 18, 46, 78 and 150 months of exposure, samples were extracted from the specimens to obtain chloride profiles in concrete. Although chloride profiles were obtained at each sampling period, here only surface chloride contents are analysed. These samples were extracted in the first millimetre of the exposure surfaces of specimens. The total chloride content was determined by potentiometric titration, following the procedures of the International Union of Laboratories and Experts in Construction Materials, Systems and Structures (RILEM, 2002).
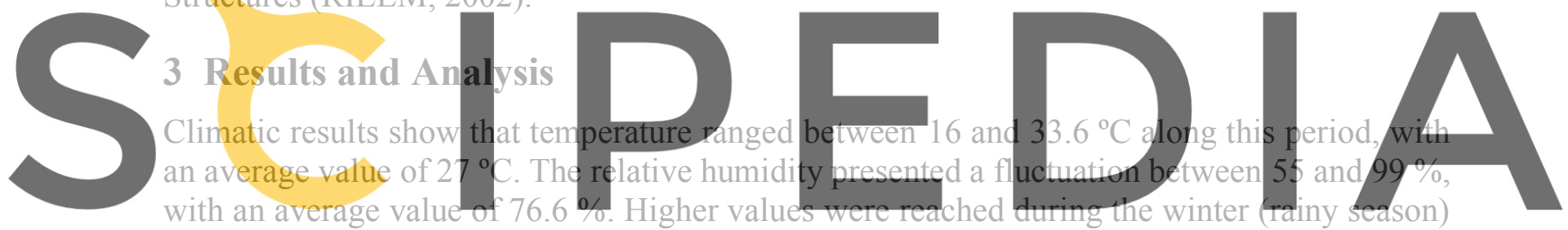
that takes place mainly between May and August. Wind speed data ranged between 1.5 and 7.6

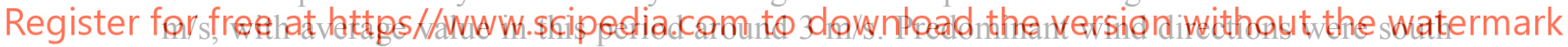

$(\mathrm{S})$, southeast (SE) and East (E), with a preponderance of SE winds. This is a typical behaviour for the studied region (Meira et al., 2006).

Average chloride deposition data are presented in Figure 2. This figure shows a strong salinity decrease in the first meters far from the sea, which may affect reinforced concrete structures in different levels. This drop in salinity is a consequence of the removal of marine aerosol salt particles due to gravimetric effect joined with other removal mechanisms (obstacles, rain, etc.).

Results of the surface chloride concentration are presented in Figure 3, considering the three different concretes and the four exposure sites and their distances from shoreline. Regarding the general aspects of the data, they show some fluctuation in the first exposure months, followed by a period of significant increase and afterwards a tendency of increase at lower rates, which suggests a tendency of reaching a maximum along time, but that was not possible to be observed in these 12.5 years of exposure. The initial fluctuation of chloride concentration in concrete surface can be attributed to the environmental interaction, where the rainfall can play an important role, due to the wash-out effect [Meira 2004, Chen et al., 2013]. 


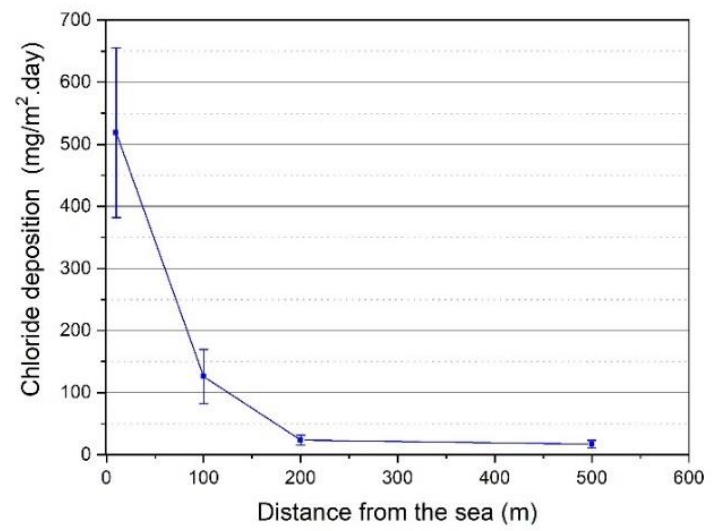

Figure 2. Average chloride deposition data during the research period.
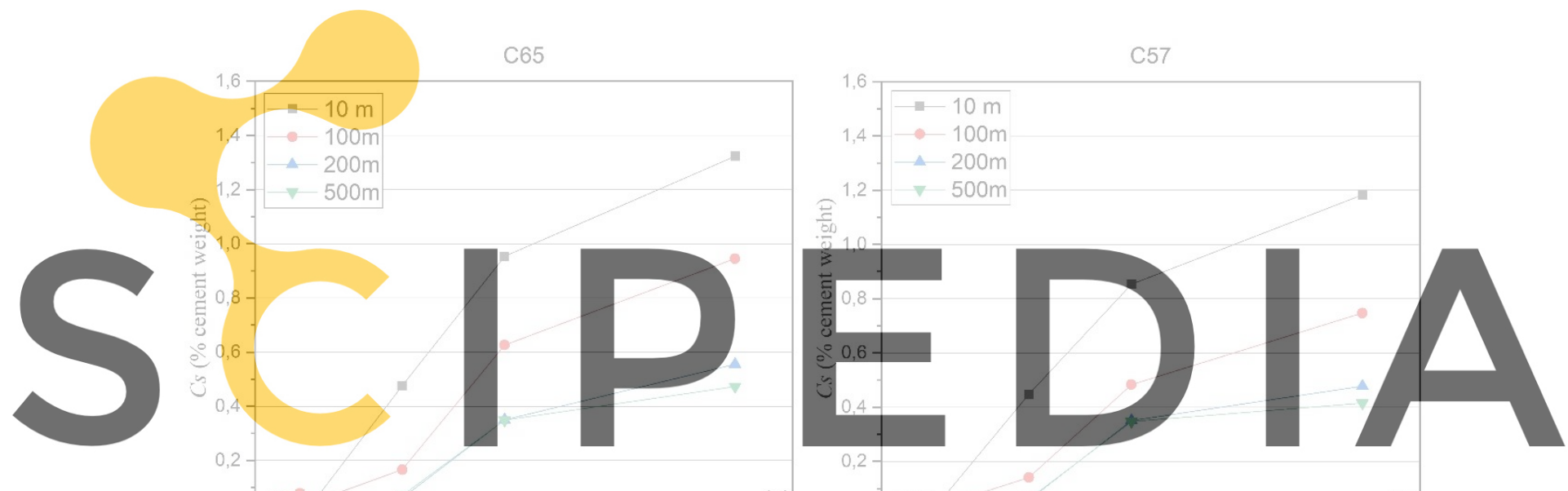

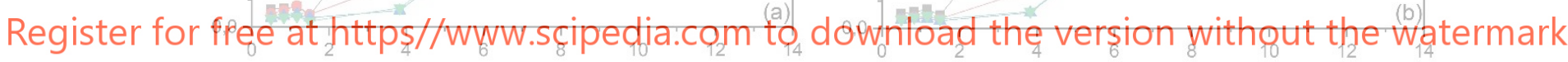

Exposure time (years)

Exposure time (years)

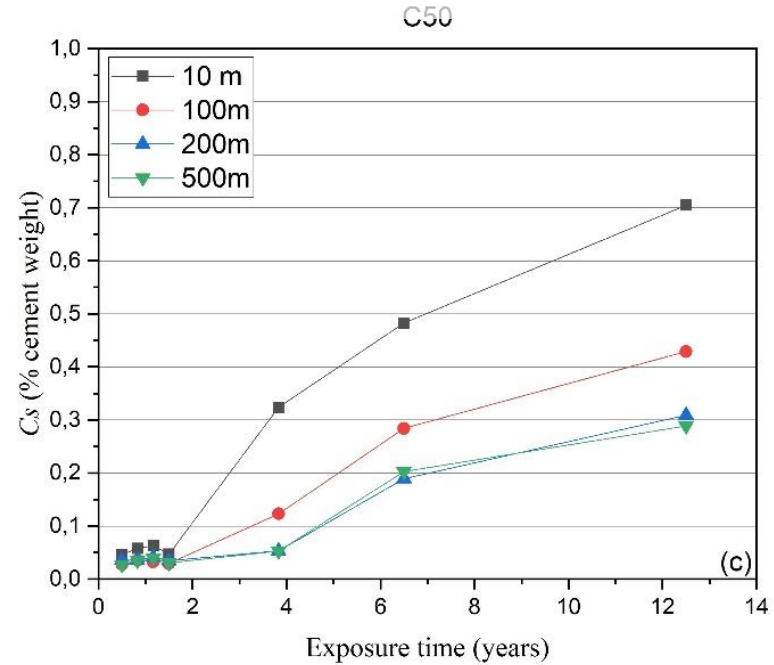

Figure 3. Behaviour of Cs along time for concretes C65 (a), C57 (b) and C50 (c). 
Regarding the influence of concrete characteristics, it is clear the higher accumulation of chlorides in concrete surface as concrete porosity increases (higher w/b). Moreover, taking into account the distance from the sea, it is noticeable the chloride concentrations decay as going far from the sea, which is a consequence of the aggressiveness decrease at sites far from the shoreline due to the lower availability of chlorides in atmosphere.

Considering that the time is not the main variable that influences $C s$ increase, but the availability of chlorides in atmosphere, it seems quite reasonable to analyse the relationship between $C s$ and the accumulated deposition of chlorides on the wet candle (Dac), which is obtained summing month-to-month the chloride deposition on the wet candle (Figure 4).

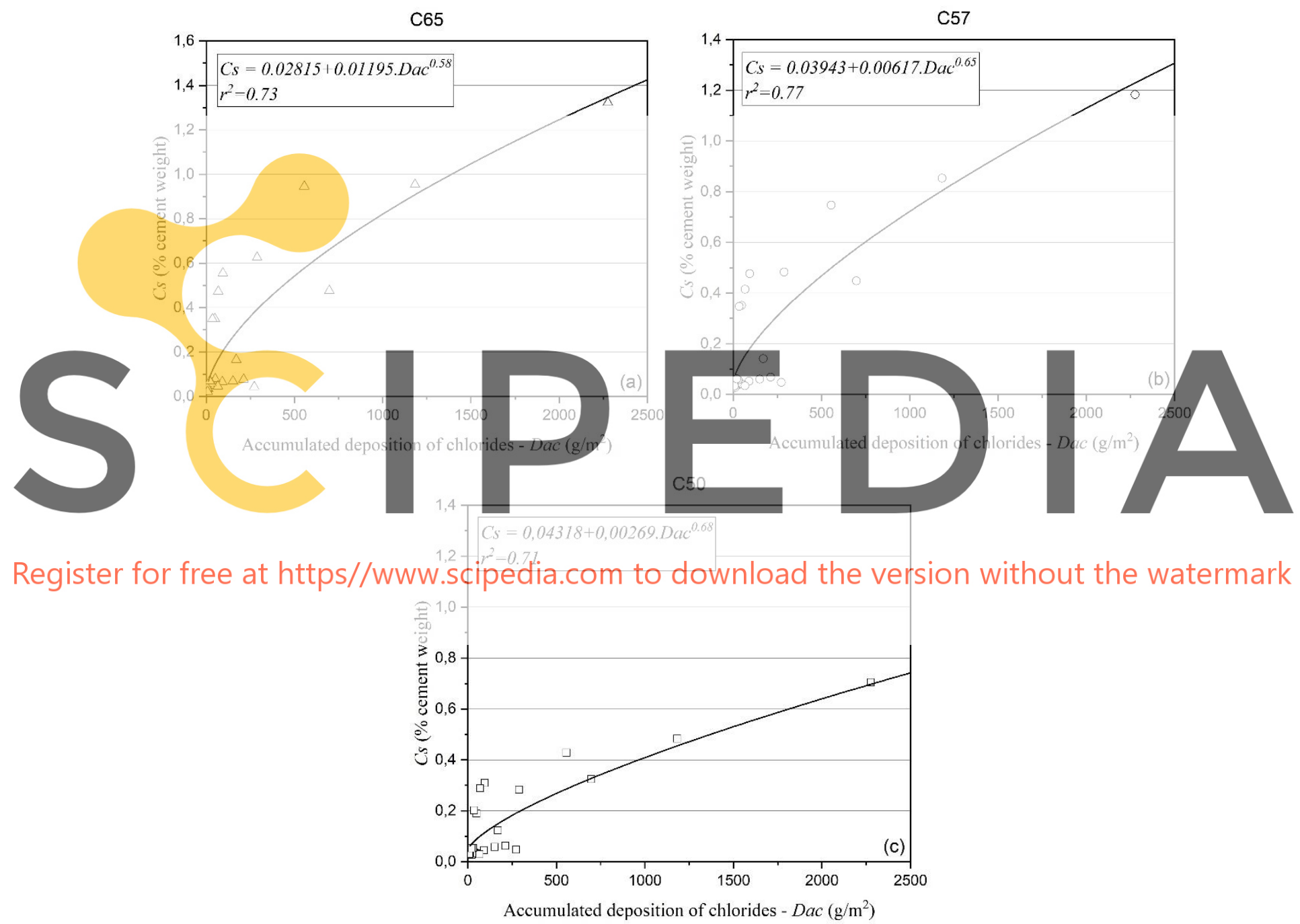

Figure 4. Relationship between $\mathrm{Cs}$ and accumulated deposition of chlorides (Dac) for concretes C65 (a), C57 (b) and $\mathrm{C} 50$ (c).

As can be seen in Figure 4, the relationship between $C s$ and Dac can be represented by the Equation (1), where $C s$ is the surface chloride concentration, $C_{0}$ is the initial chloride concentration in concrete, $k_{c s}$ is a coefficient associated to the concrete ability in capturing 
chlorides from atmosphere, Dac is the accumulated deposition of chlorides and $n$ is a coefficient associated to the rate of Dac increase along time.

$$
C s=C_{0}+k_{c s} \cdot(D a c)^{n}
$$

This Equation follows a similar way of some previous studies when considered the influence of time on Cs increase (Uji et al., 1990; Costa and Appleton, 1999; Zhou et al., 2016). However, it has the advantage of taking into account the direct relation between the chlorides present in atmosphere and those captured in concrete surface.

\section{Conclusions}

The main conclusion that can be drown up from the present analysis are:

- Cs increases along time and although tends to reach a maximum, this moment was not reached in 12.5 years of exposure time.

- Concrete porosity influences on Cs behaviour in a direct way. Concretes with higher $\mathrm{w} / \mathrm{b}$ present a faster increase of $C S$ values.

- The availability of chlorides in atmosphere plays an important role in Cs behaviour. Higher availability of chlorides means higher Cs values. However, this relationship does not follow a linear function.
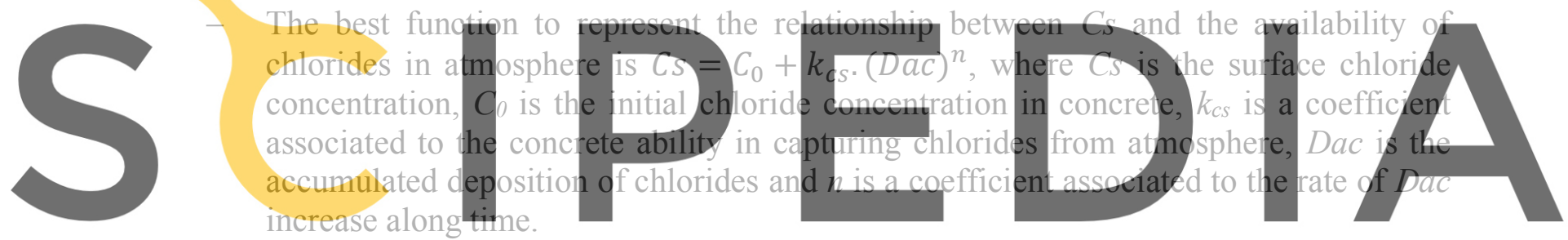

\section{Register for free at https//www.scipedia.com to download the version without the watermark} Acknowledgements

The authors thank CNPq (Brazilian National Council for Scientific and Technological Development) and the Research Laboratory on Building and Waste Materials of IFPB (Paraíba Federal Institute) for partially supporting this research. The authors also thank the Brazilian Institute of Meteorology for providing climatic data.

\section{ORCID}

Gibson R. Meira: http://orcid.org/0000-0002-2010-5315

Pablo R. R. Ferreira: http://orcid.org/0000-0002-4881-0737

Maria S. Freitas: http://orcid.org/0000-0002-9734-4242

Carmen Andrade: https://orcid.org/0000-0003-2374-0928

\section{References}

ASTM G-140-02 (2014). Standard test method for determining atmospheric chloride deposition rate by wet candle method.

Andrade, C., Sagrera, J. L. and Sanjuán, M. A. (2000). Several years study on chloride ion penetration into concrete exposed to Atlantic ocean water. In Proceedings of the Second International RILEM Worshop on Testing and Modelling Chloride Ingress into Concrete, Paris, France.

Chen, Y.S., Chiu, H.J., Chan, Y.W., Chang, Y.C. and Yang, C.C. (2013). The correlation between airborne salt 
and chlorides cumulated on concrete surface in the marine atmosphere zone in north taiwan. Journal of Marine Science and Technology, (21), 24-34.

Costa, A. and Appleton, J. (1999). Chloride penetration into concrete in marine environment - part II: Prediction of long term chloride penetration. Materials and Structures, (32), 354-359.

Kassir, M. K. and Ghosn, M. (2002). Chloride-induced corrosion of reinforced concrete bridge decks. Cement and Concrete Composites, 32(1), 139-143.

Maheswaran, T. and Sanjayan, J. G. (2004). A semi-closed-form solution for chloride diffusion in concrete with time-varying parameters. Cement and Concrete Research, 56(6), 359-366.

Meira, G. R. (2004). Chloride aggressiveness in marine atmosphere zone connected with corrosion problems in reinforced concrete structures (in Portuguese). PhD. Thesis, Federal University of Santa Catarina, Florianópolis, Brazil.

Meira, G. R., Andrade, C., Padaratz, I. J., Alonso, C. and Borba Jr, J.C. (2006). Measurements and modelling of marine salt transportation and deposition in a tropical region in Brazil. Atmospheric Environment, (40), 55965607.

Pack, S., Jung, M., Song, H., Kim, S. H. and Ann, K. Y.(2010). Prediction of time dependent chloride transport in concrete structure exposed to a marine environment. Cement and Concrete Research, 40(2), 302-312.

RILEM TC 178-TMC (2002). Analysis of total chloride content in concrete. Materials and Structures, (35), 583588.

Sandberg, P., Tang, L. and Andersen, A. (1998). Recurrent studies of chloride ingress in uncracked marine concrete at various exposure times and elevations. Cement and Concrete Research, 28 (10), 1489- 1503.

Uji, K., Matsuoka, Y. and Maruya, T. (1990). Formulation of equation for surface chloride conctent due to permeation of chloride. In Proceedings of Corrosion of Reinforcement in Concrete, Belfast, Ireland, 258 - 267.

Yang, L. F. Cai, R. and Yu, B. (2017). Investigation of computational model for surface chloride concentration of concrete in marine atmosphere zone. Ocean Engineering, (138), 105-111.

Zhou, S. (2016). Analytical model for square root increase of surface chloride concentration and decrease of
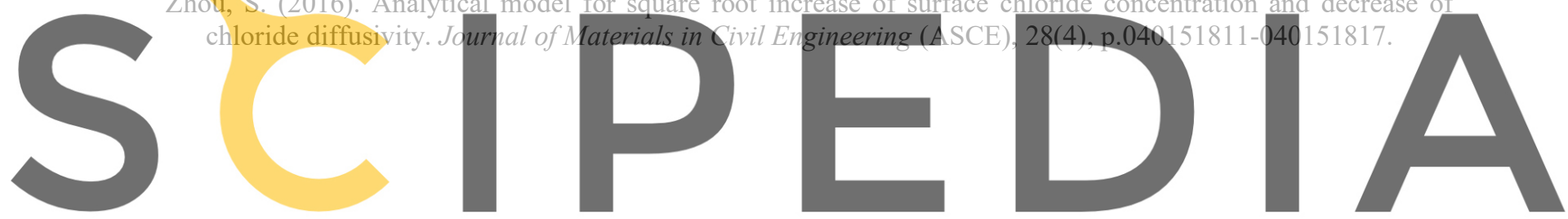

Register for free at https//www.scipedia.com to download the version without the watermark 